\title{
A IGREJA CATÓLICA APOSTÓLICA ROMANA E OS VEÍCULOS DE COMUNICAÇÃO
}

\section{ARTIGO ORIGINAL}

PINTO, Francisco Léu dos Santos ${ }^{1}$

PINTO, Francisco Léu dos Santos. A Igreja Católica Apostólica Romana e os veículos de comunicação. Revista Científica Multidisciplinar Núcleo do Conhecimento. Ano 05, Ed. 08, Vol. 07, pp. 05-15. Agosto de 2020. ISSN: 2448-0959, Link de acesso: https://www.nucleodoconhecimento.com.br/ciencia-dareligiao/veiculos-de-comunicacao

\section{RESUMO}

Este estudo busca conhecer as redes tecnológicas utilizadas pela Igreja Católica Apostólica Romana para alcançar o maior número possível de fiéis. A pesquisa foi realizada na paróquia de São Luís Gonzaga, na cidade de Irauçuba, Ceará, Brasil. Este trabalho foi embasado pelas seguintes perguntas: de que forma a Igreja interagem com os fiéis nas redes sociais? Qual rede tem a maior abrangência espacial? Quais são as redes mais acessada pelos fiéis católicos? De início a pesquisa exploratória revelou os tipos de redes tecnológica utilizada pela paróquia. No segundo momento, em uma pesquisa descritiva, foi quantificado a influência das redes tecnológicas na vida religiosa da paróquia. No terceiro momento foi necessário uma pesquisa de correção, pois foram identificadas redes tradicionais e contemporâneas. A identificação dos três principais tipos de redes utilizadas por esta instituição contribuirá para a compreensão da influência da Igreja Católica Apostólica Romana, na religiosidade dos paroquianos deste município.

1 Mestrando em Ciências das Religiões; Especialista em Geografia do Brasil; Graduado em Geografia. 
Palavras-chave: Igreja, paróquia, redes, interação, pandemia.

\section{INTRODUÇÃO}

Em tempo de pandemia a sociedade e suas instituições buscam adapta-se a nova realidade. Causado por um vírus que desafia a ciência, vivemos em um momento de distanciamento social. Hoje não se recomenda o contato físico entre as pessoas por conta do alto risco de contágio. Em muitos países, os templos da Igreja Católica Apostólica Romana encontram-se fechados. A Organização Mundial da Saúde OMS, prescreve o isolamento social como a melhor forma de combater o vírus. Nesse contesto, vários tipos de redes se apresentam como veículos capaz de interligar pessoas, instituições e até mesmo países. São os casos das redes de rádio, de televisão, telefonia móvel e a internet.

$\mathrm{Na}$ atualidade, e em meio a pandemia, cada vez mais, dependemos das redes tecnológicas. Dias (1995b) destaca as qualidades de instantaneidade e simultaneidade das redes de informação. Souza (2013) afirma que, o conceito de rede, a cada inovação técnica parece corresponder a um rejuvenescimento teóricoconceitual. Além das redes oficiais visíveis, também existem as chamadas redes ocultas ou clandestinas. Ou seja, existem vários tipos de redes dispersas em determinado espaço que pode incluir ou excluir pessoas ou instituições.

É por meio das redes que nos relacionamos, compramos, vendemos, louvamos e oramos por dias melhores. As formas de relações entre os indivíduos, os grupos ou entre instituições geram os mais diversos tipos de redes. Segundo Noronha (2015), as redes constituem elementos de identificação e pertencimento. No últimos anos a Igreja Católica Apostólica Romana intensificou a utilização dos mais diversos tipos de redes para produzir e reproduzir os hábitos religiosos. Segundo Bourdieu (2007, p. 57), os hábitos religiosos são o "princípio gerador de todos os pensamentos, percepções e ações, segundo as normas de uma representação religiosa do mundo natural e sobrenatural, ou seja, objetivamente ajustados aos princípios de uma visão política do mundo social". 
Durante décadas as redes de televisão e rádio foram as responsáveis por interligar a Igreja aos seus fiéis. As missas ou outros programas religiosos sempre estiveram presente na vida do católico romano brasileira. Hoje a Igreja é proprietária de redes de rádio e de televisão e ainda mantém programas, como a missa aos domingos, em outras emissoras. Segundo Noronha (2015), as redes formadas no campo religioso colaboram para a formação de vínculos. A rede de internet, na atualidade, é o veículo de maior utilização por pessoas físicas ou jurídicas. Nela há circulação de vários conteúdo inclusive o religiosos.

Outro tipo de rede utilizado por grande parte da sociedade é a telefonia móvel - os celulares. Este aparelho contribuiu para a interligação de vários fixos espaciais, pessoas e instituições. Os profissionais religiosos da Igreja Católica Apostólica Romana, em muitas paróquias, possuem telefone celular institucional. Somando uma rede a outra - a conexão à internet pelo celular se tornou uma das formas mais comum de se navegar na web. Instantaneamente o fiel pode receber informações sobre o papa, os cardeais, os bispos ou sobre a vida na paróquia. Em período de crise global, provocada pela pandemia, os celulares com internet se apresentam como uma das vias de interligação direta entre lgreja e fiel.

A presença do catolicismo romano na mídia foi intensificado por meio das ações da Renovação Carismática Católica Romana. Segundo Py e Reis (2015), o pontificado do papa João Paulo II estimulou o crescimento de movimentos criados por fiéis leigos que tivessem alinhamento com a hierarquia católica romana, com o intuito de trazer novos adeptos para o catolicismo romano.

Em meio a pandemia as redes tecnológicas são quase que as vias exclusivas para as formas de comunicação, formação e interação. A Igreja utiliza as redes sociais para se fortalecer. Seja no Instagram dos fiéis ou no Instagram do Papa Francisco, as redes criam o senso de comunidade desejado. Essas iniciativas, "ilustram uma reconfiguração da mediação da relação homem-sagrado por meio da midiatização da vida cotidiana nas redes sociais" (AZEVEDO; FERREIRA, 2018, p. 63). 
$\mathrm{Na}$ escala da convivência humana as paróquias são os territórios principais da Igreja. Esse espaço proporciona a identidade religiosa do devoto favorecendo o exercício da fé. Ela devem ser reconhecidas como territórios onde se dá o controle do cotidiano. Na paróquia de São Luís Gonzaga, no município de Irauçuba - Ceará, as redes de comunicação, não somente em tempo de pandemia, se tornaram vitais para o favorecimento do exercício da fé e da identidade. Os especialistas religiosos da paróquia, institucionalizados ou não, lançam mão das mais diversificadas redes para chegar até os fiéis. Seja por meio de rádio, telefonia móvel ou por internet, o objetivo é levar o evangelho a todas as criaturas da paróquia.

\section{O CONCEITO DE REDES E A IGREJA CATÓLICA APOSTÓLICA ROMANA}

As redes tecnológicas, na atualidade, são caracterizadas pelas qualidades de instantaneidade e simultaneidade. Segundo Dias (1995, p. 247), "as redes de informação emergiram mediante a produção de novas complexidades no processo histórico, da integração produtiva às modernas tecnologias de comunicação e informação". Desde o surgimento, o conceito de rede foi associado a uma verdadeira perspectiva de abordagem da realidade. Nas últimas décadas este conceito se tornou onipresente favorecido pela valorização tecnológica.

É possível fazer uma analogia entre o conceito abordado e uma rede de pesca. A trama ou a malha é gerada no encontro entre dois ou mais fios. Os nós formado pelo entrelaçamento dos fios dá estabilidade a rede. Outro exemplo de rede concreta são as vias e canais tangíveis que interligam as cidades, tais como: as ferrovias e rodovias. Estas são tipos de redes utilizadas a bastante tempo e que se fazem presentes na sociedade contemporânea.

Algumas redes, utilizadas intensamente pela sociedade atual, como a telefonia e a internet não utilizam vias tangíveis para a circulação de informação, apenas fixos espaciais - antenas de transmissões. Segundo Souza (2013), existem tipos de redes que não têm os fluxos que possam lhe dar coerência e sentido, mas apenas fixos 
espaciais que servem de meios de transmissão. As redes com fixos espaciais são bastante comuns nas cidades brasileiras. A Igreja Católica é uma das instituições que utiliza essas redes para ampliar seus espaços de dominação.

Segundo Hoch (2010, p. 48), "os meios de comunicação da era pós-industrial - rádio, TV, internet - abriram não apenas formas de comunicação modificadas, mas também novas fontes para pesquisa histórico-religiosa". Durante muito tempo a palavra sagrada esteve confinada nas Igrejas. Um novo momento de divulgação da palavra foi inaugurada com a venda de Bíblias. Hoch (2010) afirma que as transformações ocorrida em uma religião pode causar maior desenvolvimento e maior divulgação, ou a marginalização e o desaparecimento.

Em todos os lugares, a Igreja tem o papel de orientar e ajudar as pessoas. Atualmente, especialistas religiosos, podem dar orientações por várias vias, inclusive pessoalmente, por meio da leitura e interpretação da bíblia e, principalmente, pelos meios de comunicação. Desde os primórdios, a Igreja Católica utilizam-se de rede para maior divulgação de suas doutrinas. No entanto, na contemporaneidade, a mensagem religiosa está entre as que mais circulam nas redes.

Segundo Berger e Luckmann (2004, p.172) "as instituições e os universos simbólicos são legitimados por indivíduos vivos, que têm localizações sociais concretas e interesses sociais concretos". As instituições e os universos simbólico, também, são legitimados pelos meios de comunicações. Os jornais, os livros e as revistas impressos compõem esse acervo. No entanto, os veículos mais utilizados para alcançar o grande público são as redes de internet, TV e rádio.

Estas redes têm como característica comum fixos espaciais na qualidade de meios de transmissão. De acordo com Souza (2013), os fixos espaciais são utilizados para articular os inúmeros pontos do espaço, mas não depende de vias concretas para acomodar os próprios fluxos. Os fluxos disponíveis nessas redes apresentam conteúdos diversos, informações, imagens e áudios. No entanto, segundo Berger e Luckmann (2004, p. 202) "o veículo mais importante da conservação da realidade é a 
conversa". Nos últimos anos, em programas ao vivo de rádio, TV e internet as conversas com padres e líderes religiosos se intensificaram. A Igreja se apoderou desses veículos para ficar mais próxima dos fiéis.

O espaço de influência da Igreja, conectado em redes tecnológicos, se fortalece e se amplia. Segundo Camurça (2008, p. 123) "o cristianismo é uma religião proselitista, cuja mensagem direciona-se a todo mundo. Nela não há lugar para ancestrais de um clã, tribo ou povo inteiro". A Igreja Católica, em todos os Estados do Brasil, têm emissora aberta, a exemplo da TV Aparecida, Rede Vida de Televisão, TV Século XXI, TV Canção Nova, dentre outras emissoras. Os textos bíblicos, as imagens, os testemunhos de milagres ou curas são transformados em shows. Nesse cenário se destacam cantores gospel, padres e bispos. No cotidiano das paróquias católicas romanas os especialistas religiosos não medem esforços para atuarem nos meios de comunicação.

Segundo Souza (2005), para garantir a presença católica nos mais diversos veículos midiático, as dioceses investiram em marketing e atividades empresariais. Py e Reis (2015, p. 147) afirmam que "foram criadas também centenas de emissoras de rádio AM e FM. Além disso, emissoras seculares abriram espaço em sua programação para programas católicos romanos."

Para atrair cada vez mais fiéis o rádio, as emissora de TV e os portais da internet utilizam uma linguagem simples e rápida. Segundo Carranza (2000, p. 22) especialistas de dentro e de fora da Igreja "estudam o valor da internet como amplificador da mensagem religiosa". Segundo o mesmo autor, a web expande o alcance da pregação, mas não substitui a experiência presencial.

Os avanços tecnológicos contribuíram também para o ajustamento dos conteúdos religiosos. Em muitos casos, os produtos religiosos, acompanham uma lógica de mercado extremamente competitiva. Em suma, a Igreja Católica beneficia-se com a utilização das diversas redes. Em tempo de pandemia ou não, utiliza-se, as redes mais abstrata e complexas - (com fixos espaciais na qualidade de meios de transmissão - 
nós) que não utilizam vias materiais para acomodar os próprios fluxos (arcos e fios não material). Os aparelhos eletrônicos portáteis que funcionam como nós das redes, não se confundem com os fixos espaciais porque se deslocam no espaço.

\section{MATERIAL E MÉTODO}

Segundo Sampieri (1997), existem quatro tipos de pesquisa: exploratória, descritiva, correlação e explicativa. Na prática, a pesquisa pode incluir elementos de mais de um desses quatro tipos. Estes componentes do processo de investigação provoca uma variação na estratégia da pesquisa. Por isso, a escolha de um ou mais tipo de pesquisa é muito importante.

A pesquisa foi realizada na paróquia de São Luís Gonzaga no município de Irauçuba, Ceará, Brasil. Este trabalho foi embasado pelas seguintes perguntas: de que forma a Igreja interagem com os fiéis nas redes sociais? Qual rede tem a maior abrangência espacial? Quais são as redes mais acessada pelos fiéis católicos? De início a pesquisa exploratória revelou os tipos de redes tecnológica utilizada pela paróquia. No segundo momento, em uma pesquisa descritiva, foi quantificado a influência das redes tecnológicas na vida religiosa da paróquia. No terceiro momento foi necessário uma pesquisa de correção, pois foram identificadas redes tradicionais e contemporâneas. A identificação dos três principais tipos de redes utilizadas por esta instituição contribuirá para a compreensão da influência da Igreja Católica Apostólica Romana, na religiosidade dos paroquianos deste município.

As entrevistas foram realizadas com os coordenadores dos mais diversos grupos católicos romanos desta paróquia e com o padre responsável pela Pastoral da Comunicação. Um roteiro de entrevista foi previamente elaborado, a fim de obter informações sobre os tipos de redes utilizados pela Igreja Católica na cidade. Para a realização das entrevistas com os líderes religiosos dos grupos foi feito um cronograma e agendamento prévio. As informações obtidas com o padre e com os líderes religiosos foram categorizadas, analisadas e compatibilizadas com os conceitos científicos. Os fiéis também forneceram informações para a pesquisa. Para 
eles, elaboramos um questionário que foi aplicado a cento e cinquenta católicosromanos praticantes.

De acordo com Ruiz (1991), as etapas que compõem a pesquisa de campo são: pesquisa bibliográfica, determinação de técnicas de coleta, registro e análise dos dados. A pesquisa de campo consiste na coleta de dados, na observação dos fatos e no registro de variáveis presumivelmente relevantes para posteriores análises. Um estudo de caso envolve um diálogo do pesquisador com a realidade estudada para busca compreender a dinâmica dos processos.

\section{RESULTADOS E DISCUSSÃO}

Segundo Raffestin (1993), o fenômeno religioso é caracterizado por relações de poder. O poder pretende controlar e dominar os homens e as coisas. As redes utilizadas pelo catolicismo romano se destacam como mecanismo de controle, manutenção e ampliação do território religioso.

De acordo com Eliade (1992, p. 97) "seja qual for o contexto histórico em que se encontra, o homo religiosus acredita sempre que existe uma realidade absoluta, o sagrado, que transcende este mundo, que aqui se manifesta, santificando-o e tornando-o real". O ponto fixo do sagrado na paróquia de São Luís Gonzaga na cidade de Irauçuba é templo da igreja matriz. $\mathrm{Na}$ atualidade, em plena a pandemia ou não, as vias mais seguras, para acessar esse local, são as redes - de rádio, telefonia móvel e internet.

Os eventos religiosos como as missas, as novenas ou o santo terço são acessado diariamente por estes veículos de comunicação. O conteúdo religioso que circula por essas redes, também, tem por função principal satisfazer um tipo particular de interesse da Igreja Católica Apostólica Romana - manter o domínio sobre sua área de atuação.

A primeira grande rede tecnológica utilizada pela paróquia de São Luís Gonzaga foi a rede de rádio. Mais precisamente a Rádio Amizade FM 88.7. Nos dias atuais outras 
emissoras de rádios das cidades vizinhas também transmite eventos religiosos católico romanos. No entanto, grande parte da comunicação entre os padres e os fiéis é feita pela Rádio Amizade. As outras emissoras fazem cobertura de eventos pontuais católicos como a transmissão de missas dominicais. As redes de rádio não têm vias concretas para escoar os fluxos, mas apenas fixos espaciais que servem de meios de transmissão. No entanto, também, articulam os diferentes pontos no espaço.

A rede de telefonia móvel, com fixos espacial na cidade, é um outro exemplo de rede que não tem vias ou canais tangíveis concretos. Os fiéis, os líderes religiosos e os Padres utilizam-se de aparelhos celulares institucionais ou pessoais para comunicarse entre si. Segundo Fonseca e Santos (2012, p. 320), "a atuação em ou através de redes modifica de forma estrutural a interconexão entre as várias possibilidades de interligação".

A cada dia, as redes tecnologia são mais do que essenciais para a religião e para seus fiéis. Elas presenteiam o sagrado. É por estas vias que os padres apresentam o santíssimos, fazem as bênçãos e as orações de curas. O uso da internet pela Igreja, principalmente, as redes sociais demonstram uma reação plausível em meio as forças pós-modernidade de secularização. O e-mail, o blog, o Facebook, o Instagram e o WhatsApp da paróquia de São Luís Gonzaga são coordenados pela Pastoral da Comunicação.

As redes de internet apresentam uma nova maneira de se inter-relacionar. As instituições religiosas informam sobre as atividades eclesiais, prestação de serviços de informação, educação e reflexão. Na paróquia de São Luís Gonzaga, em Irauçuba, até os fiéis mais idosos passaram a acessar a rede de internet via celulares.

No ambiente entrelaçados por redes, missas, novenas, terços e outros eventos religiosos católicos romanos são transmitidos ao vivo. Segundo Eliade (1992, p. 20 21) "o homem religioso só consegue viver numa atmosfera impregnada do sagrado". O ambiente virtual também pode ser considerado mais uma técnica de consagração 
do espaço. Durante os eventos religiosos o próprio veículo de comunicação se transforma em ferramenta fundamental que liga o fiel ao sagrado.

Servindo como ferramenta primordial para a evangelização, os mais variados tipos de redes estão por todos os lados ligando e interligando ambientes religiosos, criando espaços sagrado, expandindo territórios, mesmo em tempo de pandemia ou não. Os três tipos de redes tecnológicas mais utilizados pela paróquia de São Luís Gonzaga, na cidade de Irauçuba, são: a internet, o rádio e a telefonia móvel - celular.

Quadro 1 - Tipos de redes tecnológicas mais utilizadas na paróquia.

\begin{tabular}{|l|l|}
\hline Redes & Abrangência territorial da paróquia \\
\hline Rádio & $100 \%$ \\
\hline Celulares & $100 \%$ \\
\hline Internet & $80 \%$ \\
\hline
\end{tabular}

Quadro 2 - Participação e interação dos fiéis em programas e eventos religiosos transmitido pelas redes.

\begin{tabular}{|l|l|}
\hline Redes & Porcentagem \\
\hline Celulares/Rádio & $10 \%$ \\
\hline $\begin{array}{l}\text { Celulares/notebook } \\
\text { Internet/redes } \\
\text { sociais }\end{array}$ & $90 \%$ \\
\hline
\end{tabular}

Quadro 3 - Participação nas redes sociais.

\begin{tabular}{|l|l|l|}
\hline Eventos Religiosos & Redes Sociais & Porcentagem \\
\hline Missas & Facebook e Instagram & $85 \%$ \\
\hline $\begin{array}{l}\text { Informativos, } \\
\text { convites ou avisos }\end{array}$ & WhatsApp & $90 \%$ \\
\hline
\end{tabular}




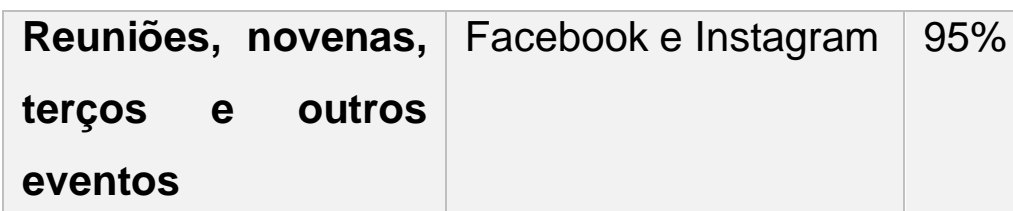

Quadro 4 - Fiéis que acompanham os eventos religiosos somente pelo rádio.

\begin{tabular}{|l|l|l|}
\hline Missas & $\begin{array}{l}\text { Informativos, } \\
\text { convites } \\
\text { aviso }\end{array}$ & $\begin{array}{l}\text { Reuniões, } \\
\text { novenas, } \\
\text { terços e outros } \\
\text { eventos } \\
5 \%\end{array}$ \\
\hline $\mathbf{1 5 \%}$ & $10 \%$ & $5 \%$ \\
\hline
\end{tabular}

\section{CONSIDERAÇÕES FINAIS}

Em tempo de pandemia a maior parte da sociedade é obrigada a se isolar. Com isso, as redes tecnológicas passaram a servir, quase que exclusivamente, como canais de acesso a vida exterior aos lares. As instituições religiosas, cada vez mais, adaptamse a nova realidade. O indivíduo para manter sua religião precisa manter ou, se necessário, produzir uma estrutura adequada de plausibilidade para dar sentido a sua vida religiosa. A Igreja Católica Apostólica Romana, por sua vez, utiliza os mais diversos canais para chegar até os fiéis.

Na paróquia de São Luís de Gonzaga, na cidade de Irauçuba, os canais de maiores acessos são a internet, o rádio e a telefonia móvel. Por estas vias circulam os conteúdos religiosos tais como as curas, as bençãos e até mesmo as penitências. $O$ primeiro veículo tecnológico de comunicação em massa utilizado por esta paróquia foi o rádio. Mesmo com os avanços tecnológicos e com o desenvolvimentos de outros meios de comunicação, o rádio ainda é o veículo de maior abrangência territorial da paróquia. A maioria do público que acessa esta mídia são pessoas acima de 50 anos de idade.

Na década de 1990 uma outra tecnologia da comunicação aportou no Brasil - os telefones celulares. Rapidamente as instituições religiosas aderiram a essa nova 
ferramenta. No entanto, de início, essa tecnologia foi utilizada, quase que exclusivamente, para a comunicação entre os membros religiosos diretamente ligados à Igreja. Atualmente, cerca de noventa e cinco por cento da comunidade religiosa da paróquia possuem celulares e podem se comunicar uns com os outros a qualquer momento.

O mundo católico-romano é um mundo mediado de canais para acessar o sagrado. No entanto, em meio a pandemia ou não, e em pleno o isolamento social ou não, uma das vias mais acessada para buscar o sagrado é a rede de internet. Essa rede juntamente com a telefonia móvel permite que os internautas acesse inúmeros ferramentas inclusive as plataformas religiosas. Na paróquia de São Luís Gonzaga, as redes sociais mais acessadas são o WhatsApp, o Instagram e o Facebook.

Diariamente as mensagens religiosas circulam nas redes sociais. As missas, as novenas, o santo terço e as orações são transmitidas ao vivos. Os fiéis interagem com orações, louvores e pedidos de bênçãos. A fé é revitalizada por meio de acessos aos conteúdos religiosos. Estes são produzidos por especialistas religiosos institucionalizados ou não. A paróquia de São Luís Gonzaga, na cidade de Irauçuba, por meio das redes, continua prestando serviços religiosos à comunidade, contribuindo de forma significativa para uma vivência de fé no sagrado, mesmo em momento de crise planetária.

\section{REFERÊNCIAS}

AZEVEDO, Bonnie Moraes Manhães; FERREIRA, Raphael da Silva. Redes sociais e religião: a Igreja Católica diante da sociedade imagética conectada. Numen: revista de estudos e pesquisa da religião, Juiz de Fora, v. 21, n.1, p. 62-80, jan./jun. 2018.

BERGER, Peter; LUCKMANN, Tomas. A construção social da realidade. Petrópolis: Vozes, 2004.

BOURDIEU, Pierre. A economia das trocas simbólicas. São Paulo: Perspectiva. 2007. 
CAMURÇA, Marcelo. Ciências Sociais e Ciências da Religião: polêmicas e interlocuções. São Paulo: Paulinas, 2008.

CARRANZA, B. Renovação Carismática: origens, mudanças, tendências. Aparecida: Santuário, 2000.

DIAS, Marco Aurélio P. Administração de materiais: edição compacta. 4 ed. São Paulo: Atlas, 1995b.

ELIADE, Mircea. O Sagrado e o Profano. São Paulo. Martins Fontes. 1992.

FONSECA, André Dioney. Os impressos institucionais como fonte de estudo do pentecostalismo: uma análise a partir do livro História da convenção geral das Assembleias de Deus no Brasil. História em Reflexão - revista eletrônica de história [online]. Dourado - MS, V. 3, n. 5, p. 1-21, jan.-jun., 2009, p. 7-8. Disponível em: <http://revista.historia.ufgd.com. br/index.php//>. Acesso em: 22 mai. 2019.

HOCH, Klaus. Introdução a ciência da religião. São Paulo: Loyola, 2010.

NORONHA, Claudia. Migração e formação de redes religiosas nas periferias urbanas: aspectos do pentecostalismo em Rio Grande da Serra. Estudos de Religião - Revista eletrônica de ciências da religião [online]. São Paulo - SP, v. 29, n. 2, p. 4367, jul.-dez. 2015, p. 59. Disponível em: < https://dialnet.unirioja.es/descarga/> Acesso em: 25 de agosto de 2018.

PY, Fábio; REIS, Marcelo Vinício de Freitas. Católicos Carismáticos e os Projetos Parlamentares de Leis. Estudos de Religião - Revista eletrônica de ciências da religião [online]. São Paulo - SP, v. 29, n. 2, p. 135-161, jul.-dez. 2015, p. 147. Disponível em: < https://dialnet.unirioja.es/descarga/> Acesso em: 25 de agosto de 2018.

RAFFESTIN, C. Por uma Geografia do Poder. Tradução Maria Cecília França. São Paulo: Editora Ática S.A., 1993. 
RUIZ, J. A. Metodologia Científica: guia para eficiência nos estudos. $3^{\text {a }}$ ed. São Paulo: Atlas, 1991.

SAMPIERI, Roberto Hernández. Metodología de la Investigación. Colombia Printed in Colombia. 1997.

SOUZA, Marcelo Lopes de. Os Conceitos Fundamentais da Pesquisa Sócioespacial. Rio de Janeiro: Bertrand Brasil, 2013.

SOUZA, André Ricardo de. Igreja in concert: padres cantores, mídia e marketing. São Paulo: Annablume: Fapesp, 2005.

Enviado: Agosto, 2020.

Aprovado: Agosto, 2020. 